\title{
Maternal and child health: gains, but a long journey ahead
}

\author{
Niranjan Kissoon MD, Sagar Dugani MD PhD, Zulfiqar A. Bhutta MD PhD
}

$\mathrm{F}$ ifteen years ago, the Millennium Summit of the United Nations resulted in the Millennium Declaration, in which all 189 member states committed to achieving eight "millennium development goals" by 2015. These ambitious goals included eradicating poverty, achieving universal primary education, improving health and environmental sustainability and developing global partnerships for development.

As we anticipate the launch of the post-2015 agenda - sustainable development goals were launched in September 2015 - it is important to reflect on the lessons we have learned thus far, and particularly the progress that has been made on development goals 4 and 5: reducing child mortality and improving maternal health. In addition, we discuss the global responsibility and strategy for achieving equity in global health.

Millennium development goal 4 called for a two-thirds reduction between 1990 and 2015 in mortality among children under five years of age. Data on child mortality come from the Global Burden of Disease Injuries, and Risk Factors (GBD) Study (involving 187 countries), ${ }^{1}$ the UN Inter-agency Group for Child Mortality Estimation $^{2}$ and Countdown to 2015: Maternal, Newborn \& Child Survival (which monitors 75 priority countries that account for more than $90 \%$ of global childhood mortality).

During the period from 1990 to 2013, the GBD study reported a $42 \%$ decrease in mortality among neonates and a 52\% decrease in mortality among children aged 1-59 months, ${ }^{1}$ which was consistent with data reported by Countdown to 2015 and the UN. In 2014, however, it was still estimated that about 18000 deaths occur daily, most of which are from preventable causes such as infection or complications during birth, ${ }^{3,4}$ with the greatest burden in sub-Saharan Africa and South Asia. Despite the nearly 50\% decrease in child mortality, stillbirths have neither decreased nor received attention. ${ }^{4}$ Moreover, these improvements have not been uniform across countries or populations. For example, only 17 of 75 monitored countries are projected to achieve goal 4, and only nine countries are expected to achieve goal $5 .{ }^{5}$
Childhood mortality is inextricably linked to maternal health, and goal 5 targeted both a threequarters reduction from 1990 levels in the maternal mortality ratio and universal access to reproductive health by 2015. Maternal death has decreased by $45 \%$ from an estimated half million deaths in $1990,{ }^{4}$ and access to reproductive health has improved, with increased coverage by skilled birth attendants in both rural and urban areas. ${ }^{6}$ Despite these advances, more than $50 \%$ of maternal deaths in low- and middle-income countries are due to complications related to pregnancy and childbirth. In addition, many deaths are caused by pre-existing medical conditions such as diabetes, obesity and HIV, which can be aggravated by pregnancy. Furthermore, more than 140 million women worldwide do not have access to voluntary family planning.

The substantial progress that has been made in maternal and child health has shown the strength in collaborations among governments, civil societies, international organizations and private-public sectors. However, Countdown to 2015 has consistently highlighted substantial disparities between and within countries, with only nine of the countries enrolled in the GBD study likely to achieve both goals. ${ }^{3}$ Much work remains, and lessons from positive outliers can be useful. For example, improvements seen in Bangladesh were unprecedented. The country has the lowest infant and child mortality (under five years of age) in Southeast Asia despite spending less money than its neighbours. ${ }^{7}$ The success in Bangladesh can be attributed to an emphasis on gender equality, empowerment of women, school enrolment, a resilient health care system with strategic community-based service delivery and resilience to natural disasters.
Competing interests: None declared.

Disclaimer: Niranjan Kissoon and Sagar Dugani are members of the CMAJ Editorial Advisory Board and were not involved in the editorial decisionmaking process for this article.

This article was solicited.

Correspondence to:

Niranjan Kissoon, nkissoon@cw.bc.ca

CMAJ 2015. DOI:10.1503 /cmaj.150725 
Fragile states with little or no health system resilience that have suffered recent conflicts (e.g., Democratic Republic of Congo and Syria), natural disasters (e.g., Haiti) or disruption to health services as a result of the Ebola outbreak (e.g., countries in West Africa), are unlikely to achieve goals 4 and $5 .{ }^{8}$ Additional factors that drive improved maternal and child health targets include political stability, financing for stable and resilient health care systems, human resources deployed to reach marginalized populations and key investments in promoting education, empowerment and poverty alleviation.

Millennium development goals 4 and 5 cannot be examined in isolation from the other development goals. Indeed, estimates from 915 censuses and national surveys show that an increase in educational attainment in women is associated with $51.2 \%$ fewer deaths among children under five years of age. ${ }^{9}$ For every additional year of education in women, mortality for children in this age group is estimated to be reduced by $8.5 \%$.

Maternal and child health rely on interaction among families, health systems and policies within an overarching framework of stable political, economic, social, technological and environmental factors. As countries move toward building resilient health care systems, ${ }^{10}$ they must focus on both a robust primary health care system and a strong hospital system where quality care is ensured. Countries that have shown improvement, such as Bangladesh, have offered a spectrum of services: preventing and treating malaria, diarrheal diseases and pneumonia; increasing vaccination rates; improving nutritional status, breastfeeding and childbirth care; and satisfying the demand for family planning. ${ }^{\text {? }}$ Working in collaboration with primary care, a strong hospital-based system with stable referral pathways enables the success of such initiatives.

Not only did the millennium goals provide mortality reduction targets, they laid the groundwork for interventions aimed at achieving higher levels of equitable and effective care across the continuum of maternal and child services. Recent research focusing on considerations of cost-effectiveness, long-term benefits AND sus- tainable gains for women's and children's health represents a paradigm shift from traditional outcomes, such as short-term morbidity and mortality. ${ }^{11}$ Greater growth in gross domestic product through improved productivity may result in the prevention of the needless deaths of 147 million children and 5 million women, as well as 32 million stillbirths, by $2035 .{ }^{11}$ With a focus on universal health care in the post-2015 agenda, policies for women's and children's health need to be guided by the best evidence.

\section{References}

1. GBD 2013 Mortality and Causes of Death Collaborators. A systematic analysis for the global burden of disease study 2013. Lancet 2015;385:117-71.

2. Levels \& trends in child mortality: report 2013. New York: United Nations Children's Fund; 2013. Available: www.childinfo .org/files/Child_Mortality_Report_2013.pdf (accessed 2015 June 14).

3. Bhutta ZA, Black R. Global maternal, newborn, and child health—so near and yet so far. N Engl J Med 2013;369:2226-35.

4. Requejo JH, Bhutta ZA. The post-2015 agenda: staying the course in maternal and child survival. Arch Dis Child 2015; 100(Suppl 1):S76-81.

5. Wang H, Liddell CA, Coates MM, et al. Global, regional, and national levels of neonatal, infant, and under 5 mortality during 1990-2013: a systematic analysis for the Global Burden of Disease Study. Lancet 2014;384:957-79.

6. Millennium development goals report; Geneva: United Nations; 2015. Available: www.un.org/millenniumgoals/news.shtml (accessed 2015 June 14).

7. Abed FH. Bangladesh's health revolution. Lancet 2013;382: 2048-9.

8. State of the world's mothers 2014: saving mothers and children in humanitarian crises. Toronto: Save the Children; 2014. Available: www.savethechildren.org/atf/cf/\% 7B9def2ebe-10ae-432c-9bd0df91d2eba74a\%7D/SOWM_2014.PDF (accessed 2015 June 21).

9. Gakidou E, Cowling K, Lozano R, et al. Increased educational attainment and its effect on child mortality in 175 countries between 1970 and 2009: a systematic analysis. Lancet 2010;376: 959-74.

10. Wulff K, Donato D, Lurie N. What is health resilience and how can we build it? Annu Rev Public Health 2015;36:361-74.

11. Stenberg K, Axelson H, Sheehan P, et al.; Study Group for the Global Investment Framework for Women's Children's Health. Advancing social and economic development by investing in women's and children's health: a new Global Investment Framework. Lancet 2014;383:1333-54.

Affiliations: University of British Columbia and British Columbia Children's Hospital (Kissoon), Vancouver, BC; Department of Internal Medicine (Dugani), Brigham and Women's Hospital, Boston, Mass.; Centre for Global Child Health (Bhutta), The Hospital for Sick Children, Toronto, Ont.

Contributors: All of the authors made substantial contributions to the conception and design of the article; the acquisition, analysis and interpretation of data; and the drafting of the article and its revision for important intellectual content. All of the authors approved the version of the article to be published and agree to act as guarantors of the work. 